\title{
Multi-Rotors Unmanned Aerial Vehicles Power Supply and Energy Management
}

\author{
Salwa Elouarouar ${ }^{1,2^{*}}$, and Hicham Medromi ${ }^{1}$ \\ ${ }^{1}$ EAS Research Group, LRI Laboratory, ENSEM, University of Hassan II, 20000 Casablanca, Morocco \\ ${ }^{2}$ LPRI, EMSI, Casablanca, Morocco
}

\begin{abstract}
Interest in electric unmanned aerial vehicles (UAVs) has grown rapidly in recent years, and their applications have expanded and diversified considerably since they first appeared, for both commercial and private purposes. Thanks to their ability to perform challenging and hazardous tasks with high mobility, safety, and low cost. As academic researchers, we are concerned with commercial multi-rotor UAVs, which are revolutionizing many public services, including search and rescue operations, wireless coverage, delivery services, precision agriculture, wildlife surveys, and real-time surveillance. One of the UAVs main issues when it comes to mobility is the limited energy autonomy/endurance. Many types of power supplies can be implemented in UAVs, each with its specific strengths and shortfalls in terms of size, charging/discharging time, energy density and power density. This paper focuses on UAVs energy aspect, with a comprehensive review of the main power sources available for multi-rotors UAVs, and energy management systems to uncover gaps and provide further insights and guidelines for future research.
\end{abstract}

\section{Introduction}

An unmanned aerial vehicle (UAV), or drone is a flying robot, capable of operating autonomously or remotely to perform a specific mission [2]. UAVs or Drones have attracted significant interest in recent years thanks to advances in sensing technologies, microprocessors, data processing, high density power storage and artificial intelligence [3]. Motivated by several advantages such as low cost and high mobility, UAVs are finding applications in both military and civil fields. Indeed, several multinational companies are investing massively in improving the performance of drones so as to extend their uses as far as possible. The drone market value is currently forecast to be worth USD26.3 billion in 2021, rising to USD 41.4 billion by 2026 [4]. In 2018, the German company Drone Industry Insights [5] ranked the top 20 operators in the drone industry, as illustrated in Figure 1.

UAVs power supplies are typically classified into two main categories: Internal Combustion Engine (ICE)-powered UAVs and Electric UAVs. Internal combustion engine (ICE) fuelled drones have greater endurance given the high energy and power densities of the ICE [6]. However, they require an auxiliary starting motor, their control is to a higher degree of complexity [7], on top of their high acoustic (noise) and thermal signatures. Electric UAVs are basically battery-powered drones, which are preferred for certain key characteristics that include high-level efficiency and reliability reducing crash risk due to motor failure [8,9], low cost, zero pollutants emission, low acoustic (noise) and thermal signatures [6], self-starting feature [7], well advanced electronic control devices and ease-adaptation to automatic control leading to a great manoeuvrability. In view of increasing the drone's energetic autonomy, one could consider taking advantage of both the electric motor with the ICE by combining both in one hybrid architecture. Such an idea has already been developed by $[6,7,10-12]$. However, the rise in greenhouse gas (GHG) emissions and the fossil fuels depletion have diminished interest in ICE and are encouraging the use of electric propulsion as a green technology. This trend is already gaining traction within UAVs to promote more environmental-friendly aircrafts. This may be part of the motivation to abandon the thermal engines in drones, at least for missions not requiring long endurance.

Electrically propelled UAVs supplies primarily electric power from electrochemical batteries. To recall, an electrochemical battery provides electrical energy by direct conversion of chemical energy [1]. The batteries on offer currently can come in a variety of technologies. A careful comparison of the existing technologies has been treated in our previous work [1]. Based on that comparison, it was concluded that Lithium-Polymer (LiPo) batteries are the best suited for aerial robotics, thanks to their high energy density, high voltage, small size, lightweight, low self-discharge, and long lifetime. The batteries, however, may suffer from some cons, such as slow charging and discharging time, expensive cost. In addition, the energy stored in a battery is rather limited by its size, which prevents the drone form having sufficient flight-time, while increasing the number of batteries is not a practical solution due to weight and

* Corresponding author: salwa.elouarouar@ensem.ac.ma 


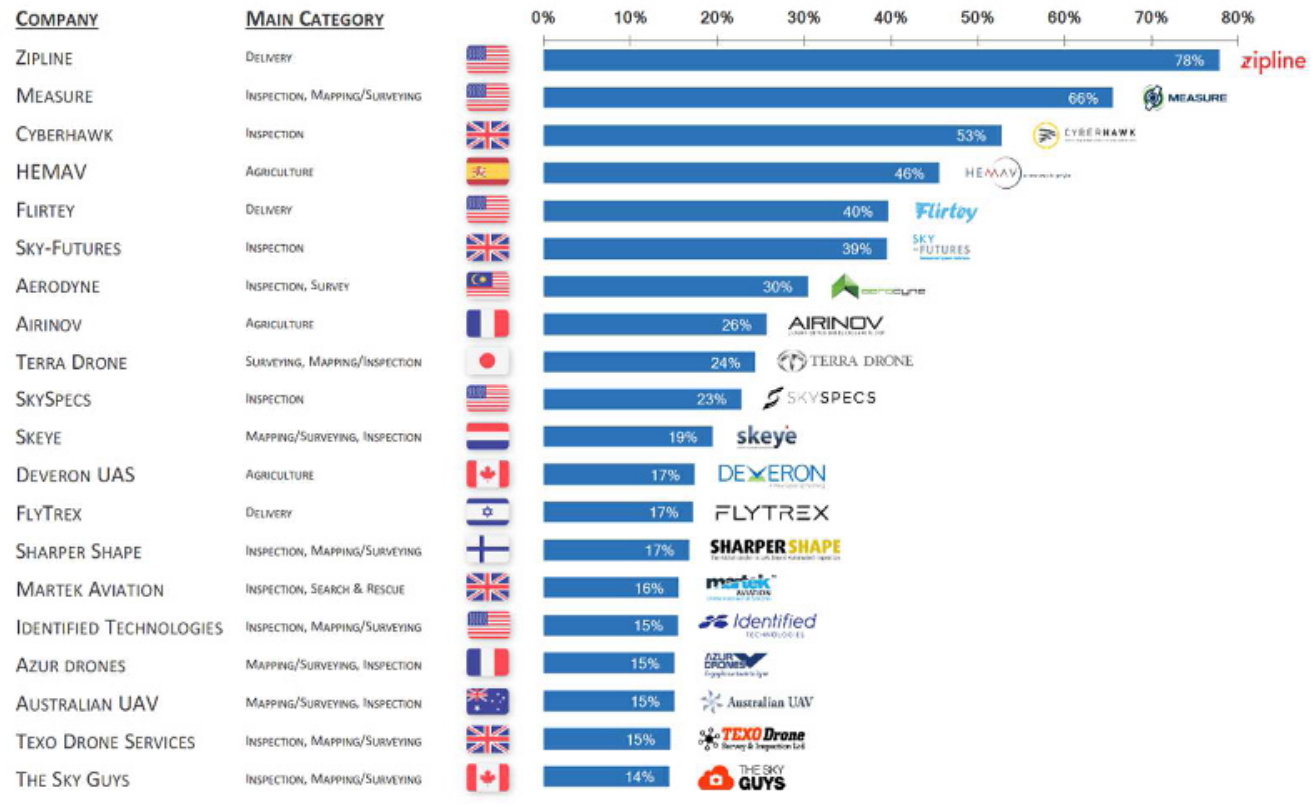

Fig. 1. Top 20 Drone operators ranking in 2018.

space restrictions. The battery may also not allow a drone to perform certain manoeuvres demanding fast power response due to its slow power dynamics. Within this context, a supercapacitor is a great option to compensate the battery's limitations. At this point, it is clear that to increase the UAV's endurance, it may be necessary to use supplementary power sources to overcome batteries limitations while respecting weight and space constraints. Beyond batteries, a fuel cell appears to be a promising candidate due its high energy density and quasi-instantaneous refuelling. It can potentially deliver up to five times higher energy density than LiPo batteries, leading to a significant increase in the UAV's endurance [13]. Beside fuel cells, a supercapacitor can contribute to the power supply process as well, as it offers a very high-power density and fast response to the peak power required for takeoffs and sudden manoeuvres of drones.

Considering these elements, hybridisation of the power supply, by combining two or more energy sources, now appears to be the most attractive option to ensure a high endurance for a UAVs. The choice of the power supply structure is however crucial. Indeed, it is influenced not only by the power sources characteristics, but also by the UAV mission requirements. Along with hybridisation, it is worth noting that flight endurance can be further enhanced by aerodynamic optimisation at the UAV design stage [14].

Given this context, it is mandatory to establish an Energy Management System (EMS) to optimally monitor the power dispatch between the on-board energy sources, so as to accomplish the targeted mission efficiently and successfully. An EMS typically includes voltage and current sensors to track the power flow, converters to monitor power sources outputs, and lastly a processing unit that holds the adopted power management strategy.

This document is arranged to briefly include the following: Section 2 introduces the basic knowledge of unmanned aerial systems (UAS), covering UAS basic parts, UAVs classifications and applications. Section 3 is devoted to UAVs power supply sources, whereas
Section 4 emphasizes the UAVs energy management system.

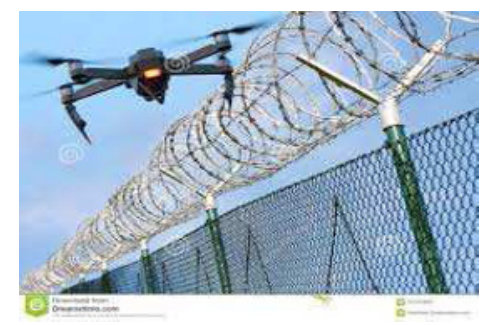

\section{Borders surveillance}

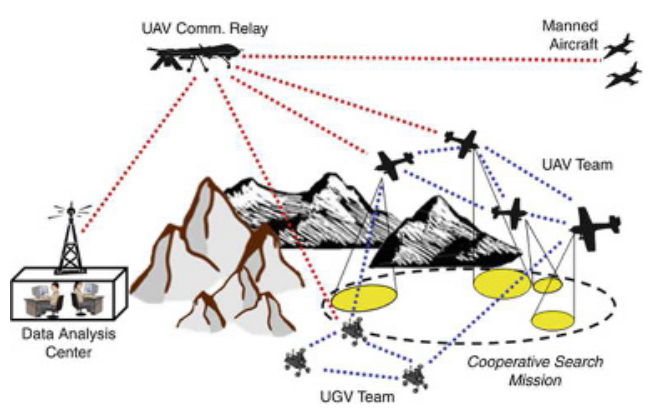

Radio and data relay

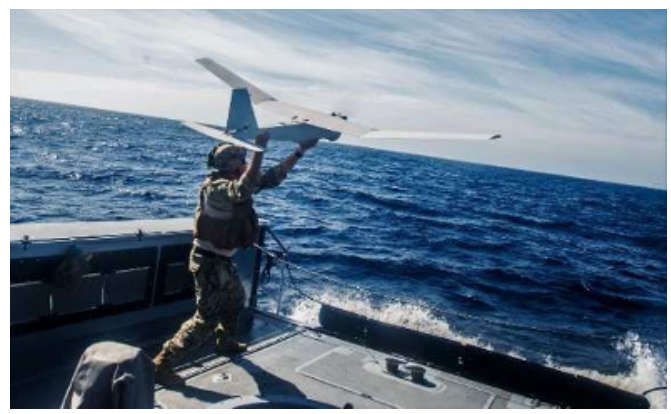

Maritime operations 


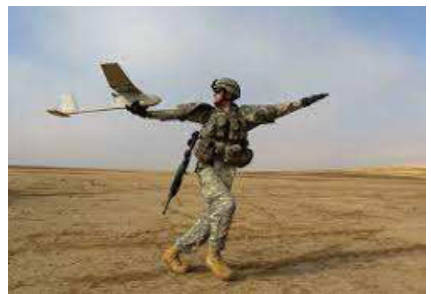

Fig. 2. UAVs military/private applications illustrations.

\section{Unmanned Aerial System Basic Knowledge}

The designation of Unmanned Aerial Vehicle (UAV) is very limited, since it only covers an aerial vehicle. It is therefore more convenient to use the designation of Unmanned Aerial Systems (UAS) when discussing in a general way. It will be shown in what follows that UAV is a component of UAS.

\subsection{UAS Basic Parts}

UAS is basically composed of two fundamental parts, as pictured in Figure 3. The air segment and ground segment are linked by a wireless connection, ensuring communication and data links between the UAV platform and the GCS.

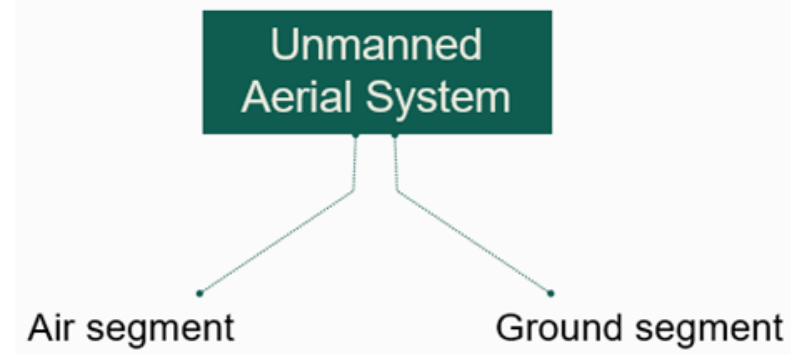

Fig. 3. Unmanned Aerial System basic parts.

\subsubsection{Air segment}

The air segment is composed of the UAV platform, which includes:

- An onboard flight control system based on a processing unit managing key tasks, including mission planning, in-flight data collection and analysis, Guidance, Navigation and Control (GNC) algorithms, and communication with the ground station.

- A propulsion system comprising power supply sources, electronic speed controllers (ESC), BLDC motors, propellers, and if requested an energy management system and converters.

- The necessary sensors to sustain an autonomous flight.

- The payload which consists of the required equipment for the missions, among others the actuators, the optical sensors or cameras, and the radars/LIDAR/SAR, etc.

\subsubsection{Ground segment}

The ground segment is commonly known as the Ground Control Station (GCS), which can be autonomous or human-operated. The GCS contains:

- Computers for monitoring and control,

- Power source,

- Communication modules.

\subsection{UAVs Classifications}

There are several criteria that can be regarded to classify UAVs such as size, fuselage (rotary wings, fixed wings, flapping wings, or hybrid) [15], endurance, flight range, maximum take-off weight (MTOW), flying mode (lighter than air, heavier than air) [16], and application or mission. Therefore, we cannot recognise a unique classification in the literature.

\subsection{UAV Applications}

Thanks to academic research and industrial projects advances, UAVs have gained applications in several fields, in both military and civil areas.

\subsubsection{Civil applications}

The civil UAV sector has experienced a high growth rate due to numerous technological innovations and the miniaturization of these engines. At present, civil drones or commercial drones, are very successful, and some of their applications are agriculture, chemical industry, forest conservation, construction, traffic monitoring, delivery, filmmaking, mining, oil and gas, power generation, public safety, mobile telecommunications, infrastructure management, sewer maintenance, environmental monitoring, natural risk management, etc (Figure 4).

\subsubsection{Military applications}

Initially, drones were confined to military applications. They were later extended to the civilian sector. In the military domain UAVs are generally referred to as drones, unlike the civilian domain where the designations, UAV and drone are identical. A couple of well-known military applications are delivery of equipment and supplies, artillery guidance, radio and data relay, communication disruptors and electronic warfare, reconnaissance flights, borders surveillance, spy drones, maritime operations (naval fire support, anti-ship missile defence, over the horizon targeting), minesweeping raking, and so on (Figure 2). 


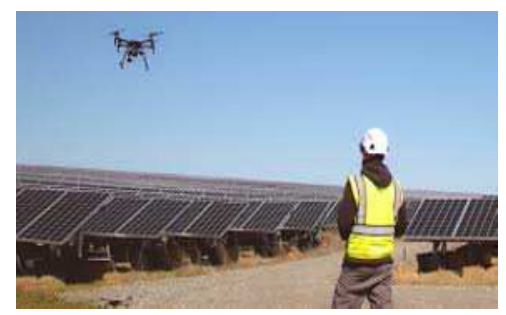

UAV-based infrastructures inspection

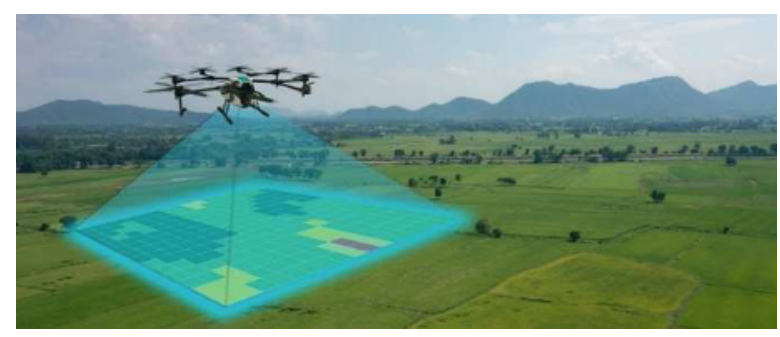

\section{UAV-based precision agriculture}

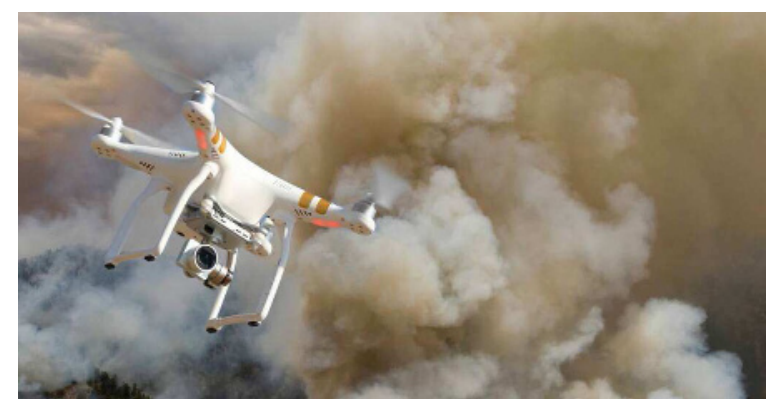

UAV-based environmental monitoring

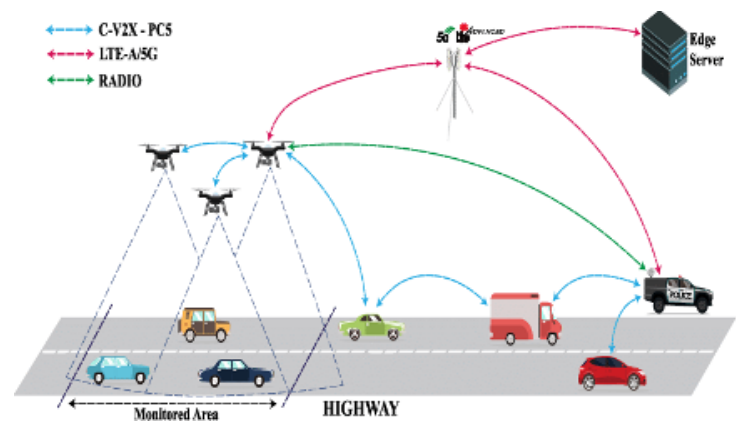

UAV-based traffic monitoring

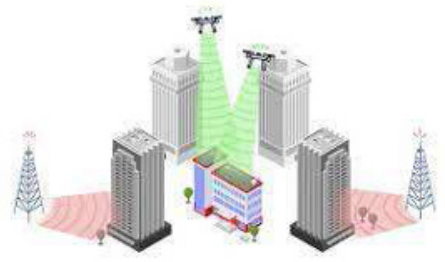

UAV-based wireless coverage

\footnotetext{
$\dagger$ A multi-rotor or multi-copter is a rotorcraft with more than two lift-generating rotors.
}

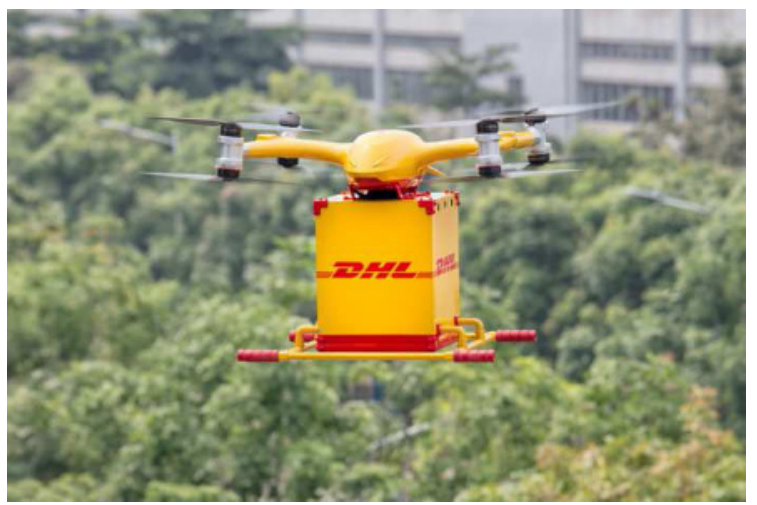

\section{UAV-based delivery services}

Fig. 4. UAVs civil/commercial applications illustrations.

\section{UAV Power Sources}

In contrast to the internal combustion engines (ICEs), electric motors (EMs) are preferred for multi-rotors ${ }^{\dagger}$ UAVs due to many key features as listed in the introductory section. In this section, we will focus on the electric propulsion-based UAVs, thus discussing electric power sources supplying UAVs.

\subsection{Battery-powered UAVs}

Batteries are considered as the core component in battery-powered UAVs [17]. In fact, most small UAVs, especially multi-rotors; which include quadrotors, hexarotors, octarotors; are battery-powered drones. Moreover, battery-based UAV platforms can improve the simplicity and the flexibility of the propulsion system, besides satisfying a range of hobbyist applications in terms of flight time and costeffectiveness. However, battery-powered UAVs tend to have a short endurance, they can operate for no more than 90 minutes with LiPo batteries [18], due to the weight constraints of the battery pack. Hence, batterypowered drones are usually devoted for civilian purposes. Based on [19], Table 1 lists the main characteristics of four types of battery technologies. Such a comparison will be helpful in selecting the technology for a UAV with a specific mission and application.

Table 1. Comparison of different batteries.

\begin{tabular}{|c|c|c|c|c|}
\hline Characteristic & Ni-Cd & Ni-Mh & LiPo & Li-S \\
\hline $\begin{array}{c}\text { Specific } \\
\text { energy } \\
\text { (Wh/kg) }\end{array}$ & 40 & 80 & 180 & 350 \\
\hline $\begin{array}{c}\text { Energy } \\
\text { density } \\
\text { (Wh/l) }\end{array}$ & 100 & 300 & 300 & 350 \\
\hline $\begin{array}{c}\text { Specific } \\
\text { power } \\
(W / k g)\end{array}$ & 300 & 900 & 2800 & 600 \\
\hline
\end{tabular}


In accordance with the above-mentioned facts, one of the biggest challenges with battery powered electric aerial vehicles is the limited autonomy or endurance. Intensive research efforts have therefore been dedicated to enhancing battery performances to increase their operational time and allow long-duration missions. Advances in batteries technology have led to the birth of the Lithium technology, which includes LithiumPolymer (Li-Po), Lithium-Ion (Li-Ion) and LithiumSulfur (Li-S) batteries. Table 1 also validates the fact that the Lithium technology stands out amongst the other technologies and proves to be interesting for aerial vehicles. Nevertheless, the specific energy of Lithium battery still limits UAVs endurance. Therefore, they will not meet the needs of many drone applications. Consequently, several alternative solutions have been proposed in the literature to overcome the battery limitations, the fuel cell is one of those alternatives.

\subsection{Fuel Cell Powered UAVs}

Fuel cell is an electrochemical cell that converts the chemical energy of hydrogen or other fuels to cleanly produce electricity. The cells necessitate a continuous supply of fuel and an oxidizing agent (usually oxygen) to sustain the chemical reactions that generate electricity. As a result, these cells can constantly produce electricity until the fuel and oxygen supply is cut off. Three techniques are currently employed to store hydrogen in UAVs [20]: compressed hydrogen gas, liquid hydrogen, and chemical hydrogen production.

Compared to battery-powered UAVs, Hydrogenpowered UAVs are capable of flying for hours instead of few minutes [21]. [13] reports that LiPo batteries possess a specific energy level of up to $250 \mathrm{Wh} / \mathrm{kg}$, while a fuel cell system using a compressed hydrogen tank can provide up to $1000 \mathrm{Wh} / \mathrm{kg}$ [18]. Furthermore, the refuelling process is almost instantaneous, versus the time-consuming process of recharging batteries. Figure 5 illustrates specific power vs. specific energy for batteries, fuel cells, and supercapacitors, and reveals that fuel cells are a clear outperformer compared to the other sources when considering specific energy.

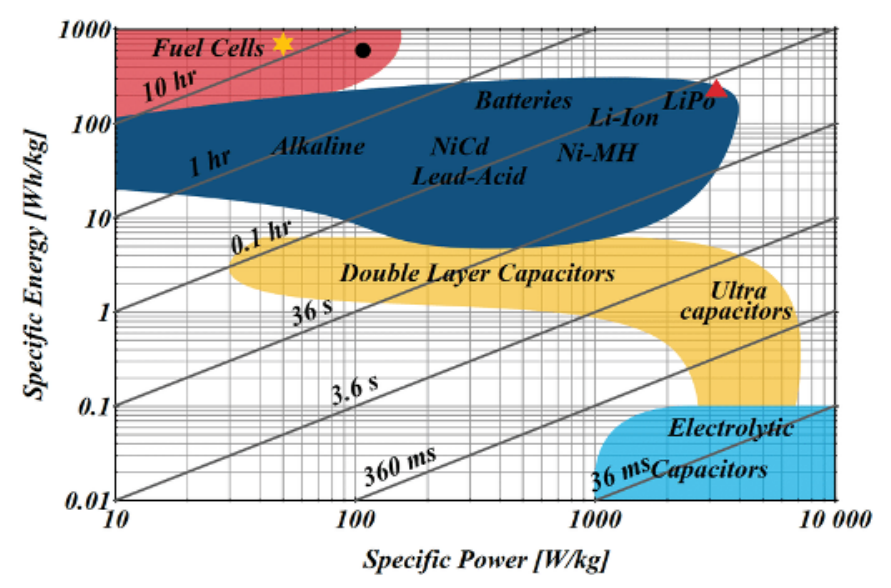

Fig. 5. Specific energy/power comparison among different energy sources [29].
Consequently, fuel cells appear as a promising alternative power source for UAVs with higher endurance expectations, due to their higher specific energy. Nevertheless, fuel cells are prone to suffer from some limitations, as for instance:

- They may possess a lower energy density when compared to Lithium batteries, as the hydrogen tank volume must be taken into account,

- Fuel cells, being a very sophisticated product, are quite expensive than other power sources,

- In practical terms, fuel cells can achieve an efficiency level of around $60 \%$, which is unfortunately not as efficient as Lithium batteries with more than $90 \%$ [22].

\subsection{Supercapacitor as an auxiliary power source}

Faster energy storage solutions are requested in several applications to complement or eventually substitute the batteries, which are known to suffer from sluggish charge/discharge cycles and reduced lifetime. Supercapacitors are an excellent example and have lately been enjoying a lot of success. A supercapacitor is typically characterised by much higher power and much lower energy densities if compared to a battery. Additionally, it performs over a wide temperature range, along with overcharge tolerance, and reasonable cost [23]. Moreover, it has a fast charging/discharging time (thus dynamic response), is non-polluting, and has exceptionally long lifetime.

In light of this, embedding a supercapacitor as a supplementary power source in UAV's hybrid power architecture will boost power density and deliver a faster power response. An investigation of a hybrid UAV propulsion system involving fuel cell, battery, and supercapacitor was conducted by the authors of [24,25]. The results demonstrated the good performance of the supercapacitor in both delivering peak power and absorbing power fluctuations during dynamic flight with rapid changes in power load.

While selecting the main and auxiliary power sources, in a hybrid power supply architecture, an EMS is mandatory to optimally manage the power flow between the on-board power sources and ensure that each power source is operating at its optimal settings to effectively accomplish the intended mission.

\section{Energy Management System}

Considering the preceding elements, we have come to the conviction that a single power source is not sufficient to satisfy the UAV's energy needs, especially when long endurance is sought. This is the reason why hybridisation is the preferred architecture to power the UAVs system. In this way, it is possible to combine the most optimal performances of different power sources and to compensate for their limitations. This means that the power needs to be optimally managed to ensure efficient and reliable energy exploitation. Thereby, an EMS must be implemented for real-time power distribution management, while considering critical 
constraints such as flight conditions; power requirements; dynamic power response; fuel consumption; battery overheating, state of health $(\mathrm{SOH})$ and state of charge (SOC) monitoring [1]; and power distribution efficiency, etc. This approach is referred to as active energy management strategy, where the power outputs are controlled through converters. In contrast, power can alternatively be distributed through a passive energy management strategy, an approach that is broadly applied in small UAVs [26,27]. In such a strategy, the power sources are directly wired to a DC bus and deliver power depending on their individual specific capacities and characteristics. No supplementary power converters or controllers are required, which significantly reduces complexity, weight, and power losses. [28] showed trough a flight simulation that the passive EMS was unable to maintain the battery's minimal SOC, which impacts its lifetime and increases the system failure possibilities. A comparison between active and passive energy management systems is given in Table 2 .

Table 2. Comparison between active and passive EMS.

\begin{tabular}{|c|l|l|}
\hline EMS & \multicolumn{1}{|c|}{ Advantages } & \multicolumn{1}{c|}{ Disadvantages } \\
\hline \multirow{5}{*}{ Active } & $\begin{array}{l}\text { - Efficiency of } \\
\text { power distribution } \\
\text { - Optimal use of } \\
\text { energy } \\
\text { - Energy system } \\
\text { security } \\
\text { - No energy } \\
\text { sources pre-sizing } \\
\text { is requested }\end{array}$ & $\begin{array}{l}\text { - Extra weight } \\
\text { - Power dissipation in the } \\
\text { converters }\end{array}$ \\
\hline \multirow{5}{*}{ Passive } & $\begin{array}{l}\text { - Simple } \\
\text { - Lightweight } \\
\text { - Power losses are } \\
\text { minimised }\end{array}$ & $\begin{array}{l}\text { - Low efficiency of power } \\
\text { distribution } \\
\text { - Energy sources } \\
\text { shortened lifetime } \\
\text { - Careful energy sources } \\
\text { sizing is necessary to } \\
\text { reliably share the DC bus }\end{array}$ \\
\hline
\end{tabular}

\section{Conclusion}

Despite the large-scale applications of drones and their ongoing development, UAVs continue to suffer from a critical issue: their limited energy autonomy or endurance. It should be noted that the propulsion system is the most energy consuming element of the UAV platform, while the consumption of the embedded electronics (avionics equipment) remains negligible. In this perspective, it was decided to focus on multi-rotors unmanned aerial vehicles power supply sources and energy management systems. Through a review of electric energy sources powering UAVs and energy management strategies, this paper attempts to provide a starting base for the development of high-performance electric propulsion systems for UAVs by facilitating the choice of the energy sources.

At this stage, it became evident that monopower source-based UAV power systems will be severely limited. This makes the hybridization of diverse energy sources a well-proven solution in designing UAV electric power system, especially if one is looking for long endurance. The right choice and sizing of the power sources to be integrated into the hybrid architecture strongly depend on UAV's mission tasks, flight duration, corresponding weight/space constraints, and even further control algorithms energy consumption.

It is worth to mention that the possibility of carrying solar cells and using solar energy in multi-rotor UAVs is also present [30], as depicted in Figure 6. But it is not an interesting solution, as long as the resulting produced energy from the solar cells is extremely limited compared to the overall UAV consumption and can at most cover the energy consumption of the onboard avionics. This is due to the platform shape which can only fit a limited number of very small solar panels (see Figure 6). However, with other UAVs configurations, such as fixed-wings drones, solar energy could be an attractive clean and cost-effective solution to power the UAV.

Otherwise, to optimally manage the hybridized power architecture and ensure efficient energy exploitation, this work also highlights the importance of integrating an energy management system for real-time power distribution management. The EMS can adopt an active or passive strategies. The choice between the two strategies depends on flight conditions; power requirements; dynamic power response; fuel consumption; battery overheating, state of health $(\mathrm{SOH})$ and state of charge (SOC) monitoring; and power distribution efficiency.

In summary, energy autonomy is a challenging concern in all dynamic applications, such as for the UAS. Achievements conducted in the field to enhance the energy autonomy, is based on the use of electric propulsion, mainly based on electric motors and electrochemical batteries. The electric propulsion has numerous advantages, compared to the classical method (such as internal fuel engines). Nevertheless, it remains insufficient to ensure a long flight duration, which is why in clear, we highly recommend powering the UAV by a hybridized architecture, which contains more than one single power source, as for instance batteries, fuel cells, supercapacitors, and eventually solar cells. This illuminates an area for improvement, as interest in UAVs is still on the rise.

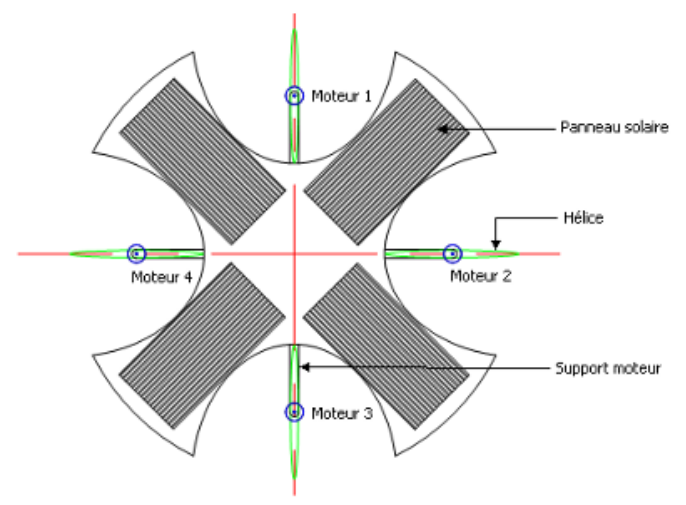

Fig. 6. Solar panels installed on a Quadrotor mini-drone [30]. 


\section{References}

1. S. Elouarouar, H. Medromi and F. Moutaouakkil, "Energy Management in Multi-Rotors Unmanned Aerial Systems," 2017 International Renewable and Sustainable Energy Conference (IRSEC), 2017, pp. 1-7, doi: 10.1109/IRSEC.2017.8477365.

2. P. Liu, A. Y. Chen, Y.-N. Huang, J.-Y. Han, J.-S. Lai, S.-C. Kang, T.-H. Wu, M.-C. Wen, M.-H. Tsai, A review of rotorcraft Unmanned Aerial Vehicle (UAV) developments and applications in civil engineering, Smart Structures and Systems pp. 1065-1094 (Jun.2014).

3. N. Adnan, S. M. Nordin, M. A. bin Bahruddin, Sustainable interdependent networks from smart autonomous vehicle to intelligent transportation networks, in: Sustainable Interdependent Networks II, Springer, 2019, pp. 121-134.

4. DRONEII.com, Global Drone Market Report 20212026 (Accessed on 23-09-2021).

5. DRONEII.com, TOP20 Drone Service Provider Ranking, March 2018 (Accessed on 22-09-2021).

6. E. Bongermino, F. Mastrorocco, M. Tomaselli, V. G. Monopoli, D. Naso, Model and energy management system for a parallel hybrid electric unmanned aerial vehicle, in 2017 IEEE 26th International Symposium on Industrial Electronics (ISIE), IEEE, Edinburgh, United Kingdom, pp. 1868-1873 (Jun. 2017).

7. R. R. Glassock, J. Y. Hung, L. F. Gonzalez, R. A. Walker, Multimodal hybrid powerplant for unmanned aerial systems (uas) robotics, In: Twenty-Fourth Bristol International Unmanned Air Vehicle Systems Conference, March 30th to April 1st 2009, Bristol United Kingdom.

8. M. Hassanalian, A. Abdelke, Classifications, applications, and design challenges of drones: A review, Progress in Aerospace Sciences 91, pp. 99131 (May 2017).

9. M. Jaeger, D. Adair, Conceptual design of a highendurance hybrid electric unmanned aerial vehicle, Materials Today: Proceedings 4 (3) pp.4458-4468 (2017).

10. Y. Xie, A. Savvaris, A. Tsourdos, Fuzzy logic based equivalent consumption optimization of a hybrid electric propulsion system for unmanned aerial vehicles, Aerospace Science and Technology 85 pp.13-23 (2019).

11. T. Donateo, L. Spedicato, Fuel economy of hybrid electric flight, Applied energy 206 pp.723-738 (2017).

12. E. Bongermino, M. Tomaselli, V. G. Monopoli, G. Rizzello, F. Cupertino, D. Naso, Hybrid Aeronautical Propulsion: Control and Energy Management, IFAC-PapersOnLine 50 (2) pp.169174 (Dec. 2017).

13. T. Kim, S. Kwon, Design and development of a fuel cell-powered small unmanned aircraft, International Journal of Hydrogen Energy 37 (1) pp. 615-622 (Jan. 2012).
14. P. Panagiotou, S. Fotiadis-Karras, K. Yakinthos, Conceptual design of a blended wing body male uav, Aerospace Science and Technology 73 pp. 3247 (2018).

15. H. Shraim, A. Awada, R. Youness, A survey on quadrotors: Configurations, modelling and identification, control, collision avoidance, fault diagnosis and tolerant control, IEEE Aerospace and Electronic Systems Magazine 33 (7) pp.14-33 (2018).

16. S. Norouzi Ghazbi, Y. Aghli, M. Alimohammadi, A. Akbari, Quadrotors unmanned aerial vehicles: A review., International Journal on Smart Sensing \& Intelligent Systems 9 (1) (2016).

17. N. A. Khofiyah, S. Maret, W. Sutopo, B. D. A. Nugroho, Goldsmith's commercialization model for feasibility study of technology lithium battery pack drone, in: 2018 5th International Conference on Electric Vehicular Technology (ICEVT), IEEE, pp. 147-151 (2018).

18. D. Verstraete, K. Lehmkuehler, K. C. Wong, Design of a Fuel Cell Powered Blended Wing Body UAV, in: Volume 1: Advances in Aerospace Technology, ASME, Houston, Texas, USA, p. 621 (Nov. 2012).

19. M. Hassanalian, M. Radmanesh, A. Sedaghat, Increasing flight endurance of MAVs using multiple quantum well solar cells, Int. J. Aeronaut. Space Sci 15 pp.212\{217 (2014).

20. A. Gong, D. Verstraete, Fuel cell propulsion in small fixed-wing unmanned aerial vehicles: Current status and research needs, International Journal of Hydrogen Energy 42 (33) pp. 21311-21333 (Aug. 2017).

21. Z. Pan, L. An, C. Wen, Recent advances in fuel cells based propulsion systems for unmanned aerial vehicles, Applied Energy 240 pp. 473-485 (2019).

22. J.-J. Hwang, J.-K. Kuo, W. Wu, W.-R. Chang, C.H. Lin, S.-E. Wang, Lifecycle performance assessment of fuel cell/battery electric vehicles, International Journal of Hydrogen Energy 38 (8) pp. 3433-3446 (2013).

23. J. Ruan, P. D. Walker, N. Zhang, J. Wu, An investigation of hybrid energy storage system in multi-speed electric vehicle, Energy 140 pp. 291306 (2017).

24. A. Gong, R. MacNeill, D. Verstraete, J. L. Palmer, Analysis of a FuelCell/Battery/Supercapacitor Hybrid Propulsion System for a UAV using a Hardware-inthe-Loop Flight Simulator, in: 2018 AIAA/IEEE Electric Aircraft Technologies Symposium, American Institute of Aeronautics and Astronautics, Cincinnati, Ohio, (Jul. 2018).

25. A. Gong, J. L. Palmer, D. Verstraete, Flight test of a fuel-cell/battery/supercapacitor triple hybrid uav propulsion system, in: 31st Congress of the International Council of the Aeronautical Sciences, p. 11, (ICAS 2018).

26. Jinming Liu, Huei Peng, Modeling and Control of a Power-Split Hybrid Vehicle, IEEE Transactions on 
Control Systems Technology 16 (6) pp. 1242-1251 (Nov. 2008).

27. M. Zandi, A. Payman, J.-P. Martin, S. Pierfederici, B. Davat, F. Meibody-Tabar, Energy Management of a Fuel Cell/Supercapacitor/Battery Power Source for Electric Vehicular Applications, IEEE Transactions on Vehicular Technology 60 (2) pp. 433-443 (Feb. 2011).

28. B. Lee, S. Kwon, P. Park, K. Kim, Active power management system for an unmanned aerial vehicle powered by solar cells, a fuel cell, and batteries, IEEE Transactions on Aerospace and Electronic Systems 50 (4) pp. 3167-3177 (Oct. 2014).

29. Q. Cai, D. J. L. Brett, D. Browning, N. P.Brandon, A sizing-design methodology for hybrid fuel cell power systems and its application to an unmanned underwater vehicle, Journal of Power Sources 195 (19) pp. 6559-6569 (2010).

30. Herinantenaina E. F., Ramanantsihoarana H.N., Rastefano E., « Synthèse de Déploiement du Système d'alimentation embarque dans un minidrone quadrirotor à énergie solaire », MADA ETI, ISSN 2220-0673, Vol.2, pp. 40-56, 2014.

31. Ashleigh Townsend, Immanuel N. Jiya, Christiaan Martinson, Dmitri Bessarabov, Rupert Gouws, A comprehensive review of energy sources for unmanned aerial vehicles, their shortfalls and opportunities for improvements, Heliyon, Volume 6, Issue 11, 2020. 